\title{
Experimental Study on the Influencing Factors of Treatment of Landfill Sludge Using Vacuum Preloading with the Fenton Reagent
}

\author{
Yajun Wu, ${ }^{1}$ Binjie Song, ${ }^{1}$ Yitian Lu $\mathbb{D},{ }^{1}$ Qingyang Deng, ${ }^{2}$ and Guang Chen ${ }^{3}$ \\ ${ }^{1}$ Department of Civil Engineering, Shanghai University, 99 Shangda Road, Shanghai, China \\ ${ }^{2}$ Shanghai Urban Operation (Group) Co., Ltd., 600 Dapu Road, Huangpu District, Shanghai, China \\ ${ }^{3}$ Shanghai Chengtou Wastewater Treatment Co. Ltd., 1164 Tianyaoqiao Road, Shanghai, China \\ Correspondence should be addressed to Yitian Lu; luyitianxxxx@shu.edu.cn
}

Received 29 March 2021; Revised 12 May 2021; Accepted 22 May 2021; Published 17 June 2021

Academic Editor: Zhongqiong Zhang

Copyright (c) 2021 Yajun Wu et al. This is an open access article distributed under the Creative Commons Attribution License, which permits unrestricted use, distribution, and reproduction in any medium, provided the original work is properly cited.

\begin{abstract}
At present, there is a lack of necessary technical parameters for sludge vacuum reinforcement. To explore the effects of the drain board type on sludge vacuum reinforcement, the Fenton reagent was used to pretreat the landfill sludge in a sludge landfill area in Shanghai, and then, vacuum preloading contrast tests of different prefabricated vertical drainage types were carried out. During the test, the discharge and settlement of sludge were recorded. After the test, the moisture content, shear strength, and appearance of PVD were measured and analysed. The main conclusions are as follows: (1) the optimum ratio of $\mathrm{H}_{2} \mathrm{O}_{2}$ and $\mathrm{Fe}^{2+}$ is 2 for the landfill sludge; (2) the total displacement and accumulated settlement of the test group with integral prefabricated vertical drainage are 1.7 times and 1.2 times those of the separate prefabricated vertical drainage, respectively; (3) the type of prefabricated vertical drainage has no effect on the distribution of water content and shear strength; and (4) when the sludge is vacuum strengthened, the integral prefabricated vertical drainage should be preferred.
\end{abstract}

\section{Introduction}

With the rapid growth of China's economy, China's sludge production is increasing, and China's total sludge production exceeded 60 million tons (based on $80 \%$ moisture content) in 2019. It is estimated that approximately $65 \%$ of the generated sewage sludge in China is disposed of in landfills, where this value is only $10 \sim 20 \%$ in EU countries. Sanitary sludge landfills can only be used as emergency treatment measures [1-3]. This method may cause serious pollution problems, and there are no other places to put sludge, such as the Shenzhen Xiaping landfill, Suzhou Qizishan landfill, or Chengdu Changan landfill $[4,5]$. After treatment of landfill sludge, the strength of landfill sludge is increased and can be used as a material for ground improvement for resource utilization [6]. Many methods can reduce the water content of landfill sludge. The method of in situ sludge treatment combined with vacuum preloading to improve the strength of soft soil foundations in landfill pits is a new method for the treatment of landfill sludge. However, there were still some other measures we should take to make it a filling material for ground improvement $[4,7]$. An increasing number of chemical agents and treatment methods have been proposed to strengthen the soft soil foundation of sludge. The vacuum preloading technique has been used to strengthen soft soil foundations and has achieved good results. After a series of treatments, the landfill sludge can be recycled, such as soil improvement, nursery planting, and fertilizer preparation. At this stage, most of the treated sludge was used for construction applications, and it can be widely used for ground improvement [8-10].

Due to the high water content of sludge, sludge needs to be dewatered to reduce the water content of sludge and increase the vane shear strength before being transported to other places to be used for ground improvement [11, 12]. The commonly used treatment and dewatering method is to add the reagent into the sludge [13-16] and then use a filter press for dewatering $[17,18]$, but not until the amount 
of sludge consolidated by this method is small and the dewatering efficiency is low. To increase the efficiency of dewatering, some researchers proposed combining preloading and reagents for the dewatering of sludge after landfills [19-21]. Preloading mainly contains surcharge preloading and vacuum preloading. Compared with surcharge preloading, vacuum preloading has two advantages: (1) vacuum preloading is usually used on the field of geotechnical engineering for the soft soil and slurry with very low strength and can be applied for a large area; therefore, vacuum preloading can treat a large amount of sludge at once; (2) sludge has a high water content and low strength, and vacuum pressure is an isotropic pressure [22] and does not cause shear failure of sludge. Vacuum preloading combined with Fenton reagent treatment is an efficient and low-cost method to make sludge for ground improvement. Fenton reagents have strong oxidation and flocculation abilities, which can destroy the extracellular polymeric substances (EPS) of sludge and react with reducing odorous substances $[2,23,24]$. Vacuum preloading can quickly discharge the water in the sludge. During the dewatering process, the sludge will be compacted and consolidated with the assistance of vacuum preloading [25]. In this process, the strength of the sludge is increased gradually. It also avoids pollution problems during secondary sludge handling. From the conditioning mechanism of Fenton's reagent combined with vacuum preloading, the Fenton reagent combined with vacuum preloading can cause more water discharge from the sludge and improve sludge consolidation efficiency [26]. There are some factors that affect the final results, such as whether the conditioning sludge reacts homogeneously with the Fenton reagent and whether the vacuum loading method is suitable, but there were few studies on the types of prefabricated vertical drainages (PVDs).

In this study, the optimum ratio of $\mathrm{H}_{2} \mathrm{O}_{2}$ and $\mathrm{Fe}^{2+}$ for the sludge treatment was judged by using the specific resistance to filtration (SRF). Two types of PVDs (integral PVD and separated PVD) were used for the vacuum preloading model test. During the test, the applied vacuum pressure was monitored. Water discharge and settlement were recorded during the dewatering process. After dewatering of sludge, the water contents for different locations were measured, and the undrained shear strength of sludge was obtained by a vane shear test. The efficiency of dewatering using different PVD types was discussed based on the test results. The flow diagram of this study is shown in Figure 1.

\section{Materials and Methods}

2.1. Landfill Sludge and Fenton's Reagent Materials. The sludge used in the test was taken from the sludge landfill area of the Bailonggang wastewater treatment plant (WWTP) in Shanghai. The sludge used in the model test is shown in Figure 1, and the basic geotechnical properties of the sludge are listed in Table 1. The sludge landfill is located in the Pudong New Area, and its location is on the bank of the Yangtze River. The surface of landfill sludge is covered with a large number of plants to prevent the spread of the sludge odour, and some backfill soil and water are exposed locally. A single sludge landfill has a length of $180 \mathrm{~m}$, a width of
$100 \mathrm{~m}$, and a depth of approximately $8 \sim 10 \mathrm{~m}$. The barrier around the landfill sludge is approximately $10 \mathrm{~m}$. A single sludge landfill can store millions of tons of sludge. Therefore, it is necessary to find the optimal method and parameters for sludge treatment.

In the experiment, $\mathrm{FeSO}_{4}, \mathrm{H}_{2} \mathrm{O}_{2}$, and dilute sulfuric acid were selected, all of which were analytically pure (AR). The experimental reagent was added according to the percentage of sludge dry basis.

\subsection{Experimental Apparatus and Procedure}

2.2.1. Vacuum Filtration Test. The details for the SRF test have been reported in the previous research [19]. In addition, the brief introduction of the SRF test is given here. Sludge dewatering relies on the pressure difference between the two sides of the filter medium (porous material), so that the water is forced through the filter medium, and the solid particles are trapped on the medium to achieve the purpose of dewatering. In vacuum filtration tests, the pressure difference is caused by vacuum pressure, and the pressure is regulated by regulating the valve to make the pressure difference constant in the whole experiment process. Vacuum filtration tests are usually used to determine the average SRF based on filtration theory. SRF refers to the resistance per unit area of sludge filtered under a certain pressure. In research on sludge dewatering performance, the specific resistance to filtration is often used as a comprehensive index [27] to measure the sludge dewatering performance. The smaller the specific resistance to filtration is, the better the dewatering performance and vice versa. The SRF refers to the resistance per unit of filtering area when per unit mass of the sludge is filtered under a certain pressure. It can be calculated as [28]

$$
\frac{t}{V}=\frac{\mu \omega r}{\left(2 P A^{2}\right)} V+\frac{\mu R_{\mathrm{f}}}{P A},
$$

where $V$ is the filtration volume $\left(\mathrm{m}^{3}\right) ; t$ is the filtration time (s); $P$ is the filtration pressure $\left(\mathrm{kg} / \mathrm{m}^{2}\right)$, which includes the pressure acting on the mud cake and on the medium; $A$ is the filtration area $\left(\mathrm{m}^{2}\right) ; \mu$ is the dynamic viscosity of the filtrate $\left(\mathrm{kg} \bullet \mathrm{s} / \mathrm{m}^{2}\right) ; \omega$ is the dry solid weight of the filtrate retained in the filter medium per unit volume $\left(\mathrm{kg} / \mathrm{m}^{3}\right) ; r$ is THE SRF (m/kg or $\left.\mathrm{s}^{2} / \mathrm{g}\right)$; and $R_{\mathrm{f}}$ is the impedance of the filter medium $\left(\mathrm{L} / \mathrm{m}^{2}\right)$.

A Buchner funnel was used to perform the filtration resistance test, as shown in Figure 2. During the test, the changes in parameters such as the vacuum pressure and the filtrate volume were recorded. The moisture content of the sludge cake was measured, and the specific resistance to filtration was calculated after the test.

The Fenton reagent consists of $\mathrm{H}_{2} \mathrm{O}_{2}$ and $\mathrm{Fe}^{2+}$ and can be used as a reagent for the treatment of landfill sludge. In the Fenton system, the ratio of $\mathrm{H}_{2} \mathrm{O}_{2}$ and $\mathrm{Fe}^{2+}$ has a large influence on the efficiency of treatment. The Fenton reagent is composed of $\mathrm{Fe}^{2+}$ and $\mathrm{H}_{2} \mathrm{O}_{2}$. Under acidic conditions, it can react to form strong oxidizing hydroxyl radicals $\left(\mathrm{OH}^{-}\right)$, which have depolymerization and destruction effects on the colloidal structure of sludge. $\mathrm{OH}^{-}$can release intracellular 


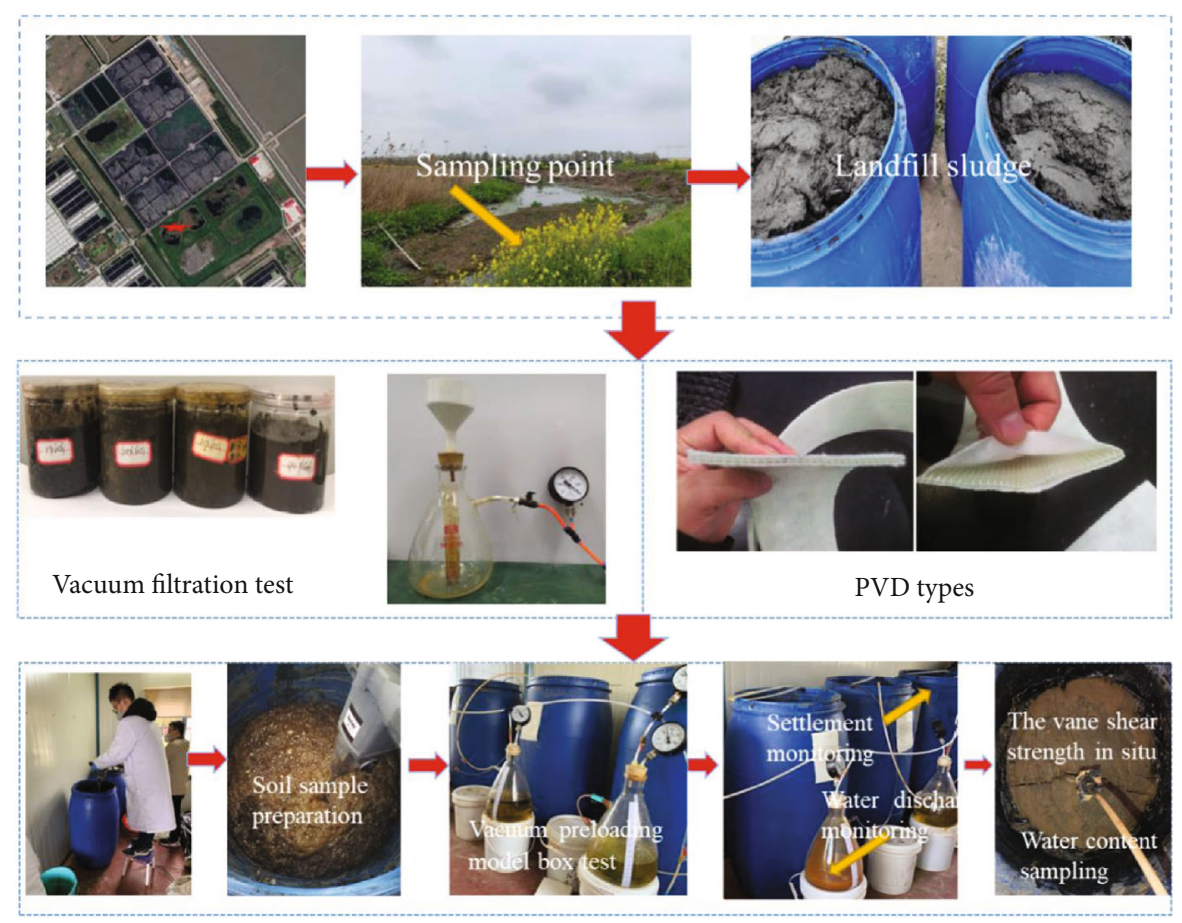

FIGURE 1: Flow diagram of this study.

TABLE 1: Basic geotechnical properties of sludge.

\begin{tabular}{lcccc}
\hline $\begin{array}{l}\text { Moisture } \\
\text { content (\%) }\end{array}$ & $\begin{array}{c}\text { Specific } \\
\text { gravity }\end{array}$ & $\begin{array}{c}\text { Organic } \\
\text { content }(\%)\end{array}$ & $\begin{array}{c}\text { Density } \\
\left(\mathrm{g} \cdot \mathrm{cm}^{-3}\right)\end{array}$ & $\begin{array}{c}\text { Permeability } \\
\left(10^{-7} \mathrm{~cm} \cdot \mathrm{s}^{-1}\right)\end{array}$ \\
\hline 76.2 & 1.8 & 40.9 & 1.12 & 1.9 \\
\hline
\end{tabular}

Note: moisture content is the mass ratio between water and sludge.

water to improve sludge dewatering performance. Neyens et al. carried out an experimental study of Fenton's reagentconcentrated sludge dewatering performance [23], which showed that the $\mathrm{pH}, \mathrm{Fe}^{2+}$ addition amount, and $\mathrm{H}_{2} \mathrm{O}_{2}$ addition amount of the sludge were the three main factors affecting the sludge dewatering performance. Wu used the $\mathrm{pH}, \mathrm{Fe}^{2+}$ addition amount, and $\mathrm{H}_{2} \mathrm{O}_{2}$ addition amount of sludge as influencing factors to perform a filtration resistance test through a three-factor four-level orthogonal test $[16,19$, $20,25]$. The drainage characteristics and permeability of the sludge modified by reagents were improved to a greater extent than those of the original sludge, and the sludge moisture content decreased significantly. It was found that the $\mathrm{H}_{2} \mathrm{O}_{2}$ addition amount had the greatest influence on the conditioning effect of the Fenton reaction; moreover, changes in $\mathrm{pH}$ under acidic conditions had little influence on the conditioning effect of the Fenton reaction. Therefore, this filtration resistance test program was aimed at exploring the influence of $\mathrm{Fe}^{2+}$ and $\mathrm{H}_{2} \mathrm{O}_{2}$ addition amount on the conditioning effect of the Fenton reaction based on the above research results. The test program is shown in Table 2. In the test, the $\mathrm{pH}$ of the sludge was adjusted to 4.0 with dilute sulfuric acid first. Then, $\mathrm{Fe}^{2+}$ solution $\left(\mathrm{FeSO}_{4} \cdot 7 \mathrm{H}_{2} \mathrm{O}\right.$ solution) was added. After mixing, $\mathrm{H}_{2} \mathrm{O}_{2}$ solution was added.
2.2.2. Vacuum Preloading Model Test. The instruments used included a measuring cylinder, an electronic balance (with a precision of $0.01 \mathrm{~g}$ ), a glass rod, a beaker, a model box (as shown in Figure 3), an air compressor, a vacuum switching valve, a vacuum gauge, a suction filter bottle, a ruler, a thin tube, an oven, PVDs (as shown in Figure 4), black sealing films, and geotextiles. The performance indicators of the PVDs are shown in Table 3.

Landfill sludge was treated by using the reagent and vacuum preloading. The types of PVDs should be considered in the project. PVDs are used for the drainage of vacuum preloading and transfer of the vacuum pressure into the soil during vacuum preloading. The PVD type influences the efficiency of vacuum dewatering of the sludge. In the vacuum preloading test, it is difficult to control the tightness of the filter membrane and core plate during the production of the separated PVD. When the filter membrane is loosely connected to the core plate, the filter membrane of the separated PVD will be embedded into the core groove under the action of vacuum pressure, which reduces the space of the drainage channel and reduces the drainage capacity of the plate. When the shape of the separated PVD bends with the deformation of the soil, the groove teeth of the core plate are easy to fall down, and the drainage channel area and water carrying capacity are greatly reduced, which will affect the vacuum preloading test. Under complex construction conditions such as vacuum preloading, the filter membrane is not easy to separate from the core plate and the groove teeth on the core plate of the integral PVD are not easy to fall over. In the study of vacuum preloading treatment of landfill sludge, the different types of PVDs have not appeared yet.

To explore the dewatering law of the modified sludge vacuum drainage of these two plastic PVDs as well as their 


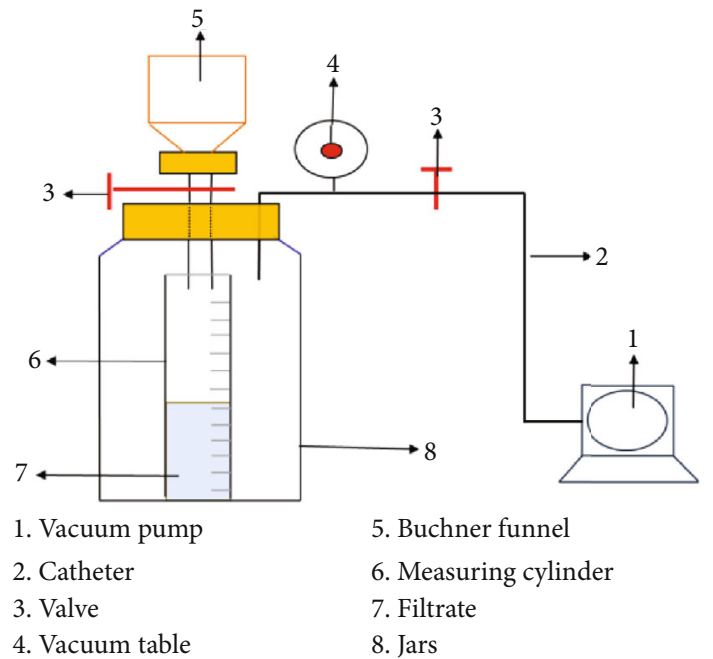

(a) Sketch of the test device

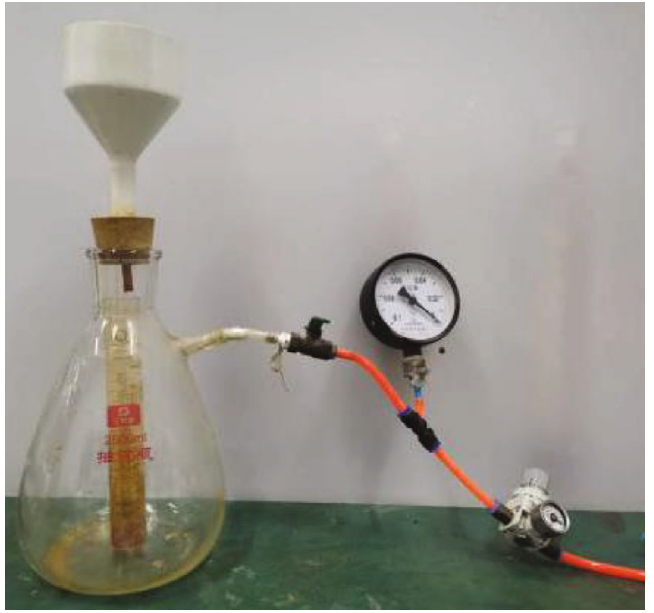

(b) Picture of the test device

Figure 2: Specific resistance test device.

TABLE 2: Reagent proportioning scheme for the specific resistance test.

\begin{tabular}{lcccccccccc}
\hline Case & 1 & 2 & 3 & 4 & 5 & 6 & 7 & 8 & 9 & 10 \\
\hline $\mathrm{H}_{2} \mathrm{O}_{2}(\%)$ & 4 & 6 & 8 & 12 & 16 & 8 & 12 & 16 & 24 & 32 \\
$\mathrm{Fe}^{2+}(\%)$ & 4 & 4 & 4 & 4 & 4 & 8 & 8 & 8 & 8 & 8 \\
$\mathrm{H}_{2} \mathrm{O}_{2} / \mathrm{Fe}^{2+}$ & 1 & 1.5 & 2 & 3 & 4 & 1 & 1.5 & 2 & 3 & 4 \\
\hline
\end{tabular}

Note: the value in the table is the mass ratio between the addition amount and dry sludge.

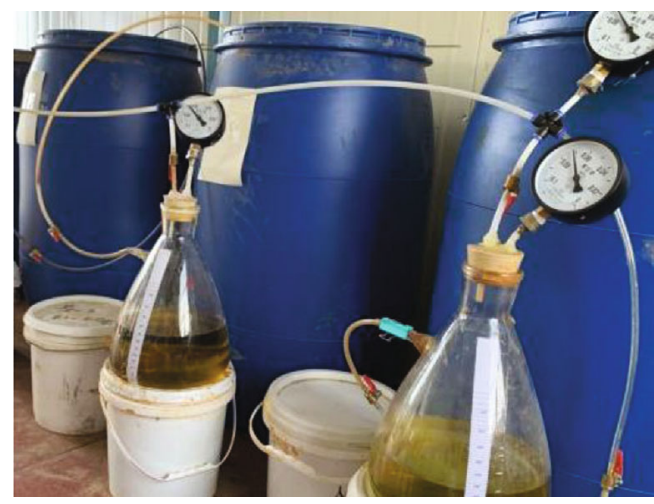

FIgure 3: Physical diagram of the test device.

difference, the treatment effects of these two plastic PVDs were compared and analysed through vacuum preloading tests. The model box is composed of a cylindrical plastic barrel and sealing cover. The height of the barrel is $980 \mathrm{~mm}$, the outer diameter is $580 \mathrm{~mm}$, and the inner diameter is $570 \mathrm{~mm}$. The design of our test equipment is based on the design of other scholars in the study of the vacuum preloading test $[26,29,30]$. The model box designed by them is composed of a cylindrical plexiglass barrel. The height of the model box is $500 \mathrm{~mm}$, the outer diameter is $600 \mathrm{~mm}$, and the inner diameter is $580 \mathrm{~mm}$. Our model box size design is the same as theirs. The height of our model box is a little higher than theirs, but the actual size of our model box is the same as theirs. This size design meets horizontal strength reinforcement and also can be used to simulate vacuum deformation characteristics of topsoil in the vertical direction. In general, the size of the model box is sufficient to meet the perspective of the depth and scope of the strength test in vacuum preloading. The vacuum preloading test is shown in Table 4.

The vacuum preloading test system was mainly composed of a model box, plastic PVDs, black sealing membranes, drain pipes, red ball valve, vacuum metre, water collection bottle, vacuum switch valve, air compressor, etc.; the PVD was connected to the water collection bottle (gasliquid separation bottle) through the drain pipe. The other end of the bottle was connected to the vacuum switching valve and the air compressor to achieve gas-liquid separation, as shown in Figure 5; to avoid excessive initial pressure, a large number of small particles migrated to the PVD and clogged the filter membrane. The vacuum load was applied in stages. The primary load was $40 \mathrm{kPa}$. After 24 hours, the load increased to $80 \mathrm{kPa}$ until the end of the test.

During the test, the vacuum degree, discharge capacity, and accumulated settlement were monitored and recorded. When the water discharge per hour is less than $15 \mathrm{~mL}$, the vacuum preloading test is considered to be stopped. After the test, several samples were taken from the sludge in the model box to measure the water content and perform the vane shear test [31]. The test points and sampling points are shown in Figure 6.

\section{Experimental Results and Discussion}

3.1. Vacuum Filtration Test Results. The relationship between the specific resistance to the filtration value and the $\mathrm{H}_{2} \mathrm{O}_{2} / \mathrm{Fe}^{2+}$ ratio is shown in Figure 7. It can be seen from the figure that the specific resistance to filtration tended to decrease with the increasing mixture ratio. When the mixture 


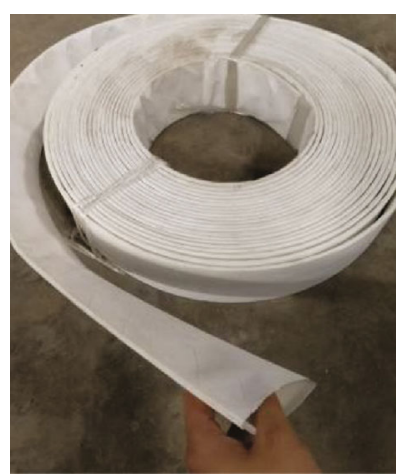

(a) The separated PVD

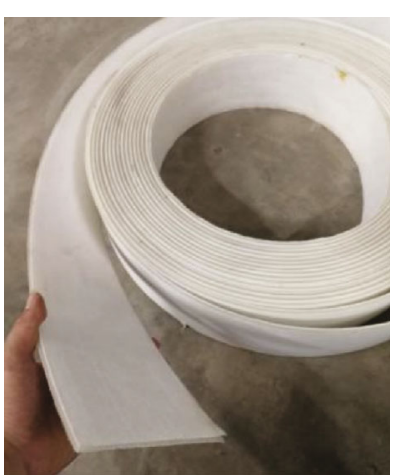

(b) The integral PVD

Figure 4: PVD.

TABle 3: Performance index of two kinds of drainage board.

\begin{tabular}{|c|c|c|c|c|c|c|c|c|}
\hline \multirow{2}{*}{ Type } & \multicolumn{2}{|c|}{$\begin{array}{c}\text { Sectional } \\
\text { dimension }(\mathrm{mm})\end{array}$} & \multirow{2}{*}{$\begin{array}{l}\text { Longitudinal } \\
\text { discharge } \\
\left(\mathrm{m}^{3} \cdot \mathrm{s}^{-1}\right)\end{array}$} & \multirow{2}{*}{$\begin{array}{c}\text { The equivalent } \\
\text { aperture of the } \\
\text { filter membrane } \\
(\mathrm{mm})\end{array}$} & \multirow{2}{*}{$\begin{array}{l}\text { Tensile } \\
\text { strength } \\
(\mathrm{kPa})\end{array}$} & \multirow{2}{*}{$\begin{array}{c}\text { The filter } \\
\text { membrane } \\
\text { permeability } \\
\text { coefficient }\left(\mathrm{cm} \cdot \mathrm{s}^{-1}\right)\end{array}$} & \multicolumn{2}{|c|}{$\begin{array}{l}\text { The filter membrane strength of } \\
\text { extension }\left(\mathrm{N} \cdot \mathrm{cm}^{-1}\right)\end{array}$} \\
\hline & $\begin{array}{l}\text { Width } \\
( \pm 2 \%)\end{array}$ & $\begin{array}{l}\text { Thickness } \\
( \pm 0.5 \%)\end{array}$ & & & & & Dry state & Wet state \\
\hline $\begin{array}{l}\text { The } \\
\text { separated } \\
\text { PVD }\end{array}$ & 100 & $\geq 4.0$ & $\geq 25$ & 0.075 & $\geq 1.3$ & $\geq 5 \times 10^{-4}$ & 25 & 20 \\
\hline $\begin{array}{l}\text { The } \\
\text { integral } \\
\text { PVD }\end{array}$ & 100 & $\geq 4.0$ & $\geq 25$ & 0.12 & $\geq 1.4$ & $\geq 5 \times 10^{-4}$ & 25 & 20 \\
\hline Condition & - & - & $\begin{array}{l}\text { Lateral } \\
\text { pressure } \\
350 \mathrm{kPa}\end{array}$ & In $\mathrm{O}_{98}$ & $\begin{array}{l}\text { Ratio of } \\
\text { elongation } \\
\text { in } 10 \%\end{array}$ & $\begin{array}{l}\text { Immersed in water } \\
\text { for } 24 \text { hours }\end{array}$ & $\begin{array}{l}\text { Ratio of } \\
\text { elongation } \\
\text { in } 10 \%\end{array}$ & $\begin{array}{c}\text { Ratio of elongation in } \\
15 \% \text {, immersed in } \\
\text { water for } 24 \text { hours }\end{array}$ \\
\hline
\end{tabular}

Note: the "condition" means the further explanation on the test condition, and all the data are obtained under these conditions.

TABLE 4: Vacuum preloading test.

\begin{tabular}{lccccc}
\hline Case & Sludge dosage $(\mathrm{kg})$ & Type of PVD & Reagent & Addition amount (amount of dry base added) & Standing time (h) \\
\hline 1 & 100 & The separated PVD & Fenton reagent & $4 \% \mathrm{Fe}^{2+}, 8 \% \mathrm{H}_{2} \mathrm{O}_{2}$ & 72 \\
2 & 100 & The integral PVD & Fenton reagent & $4 \% \mathrm{Fe}^{2+}, 8 \% \mathrm{H}_{2} \mathrm{O}_{2}$ & 72 \\
3 & 100 & The integral PVD & - & - & 72 \\
\hline
\end{tabular}

ratio reached 2.0, the specific resistance to filtration value no longer decreased. $\mathrm{Fe}^{2+}$ reacted with $\mathrm{H}_{2} \mathrm{O}_{2}$ in the Fenton reaction system to generate hydroxyl radicals $\left(\mathrm{OH}^{-}\right) . \mathrm{Fe}^{2+}$ also acted as a catalyst for the Fenton reaction. The comparison of the two curves in the figure showed that the amount of $\mathrm{Fe}^{2+}$ was not the better at the same mixture ratio because excessive $\mathrm{Fe}^{2+}$ would not only reduce $\mathrm{H}_{2} \mathrm{O}_{2}$ but also consume the effective $\mathrm{OH}^{-}$available for oxidation in the system. At the same time, it would affect the oxidation cracking effect of the Fenton process [32]; the amount of $\mathrm{H}_{2} \mathrm{O}_{2}$ was not the better. When the mixture ratio was 4 , the specific resistance to filtration value with $8 \%$ Fenton's reagent and $32 \% \mathrm{H}_{2} \mathrm{O}_{2}$ was basically the same as that with $4 \% \mathrm{Fe}^{2+}$ and $16 \% \mathrm{H}_{2} \mathrm{O}_{2}$ because when the amount of $\mathrm{H}_{2} \mathrm{O}_{2}$ was too high, $\mathrm{Fe}^{2+}$ in the system would be oxidized to $\mathrm{Fe}^{3+}$ quickly and greatly reduced the catalytic effect so that the reaction rate was reduced and the production of hydroxyl groups was inhibited [33]. Based on the test results, $4 \% \mathrm{Fe}^{2+}$ and $8 \% \mathrm{H}_{2} \mathrm{O}_{2}$ were used for the model test.

\subsection{Vacuum Preloading Model Test Results}

3.2.1. Cumulative Water Discharge. The drainage condition during vacuum preloading is shown in Figures 8 and 9. Figure 8 shows that after conditioning, the drainage rate was significantly improved compared to that of the original sludge, and the drainage rate was very sensitive to the vacuum degree. At the initial moment when vacuum pressure was applied and within 24 hours after the vacuum pressure was adjusted, the drainage rate suddenly increased. The drainage rate of the test group using the integral PVD maintained a high level in the rapid phase within the first 50 hours and then rapidly decreased into the slow phase, indicating that the pores of the sludge decreased with deepening 


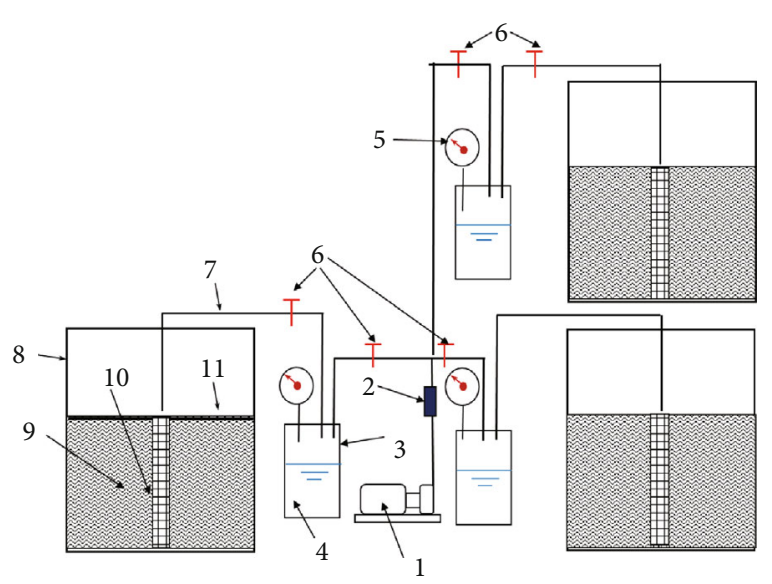

1. Vacuum pump

2. Vacuum conversion valve

7. Drain pipe

3. Jars

4. Filtrate

5. Vacuum table

6. Valve

FIgURE 5: Schematic diagram of the test device.

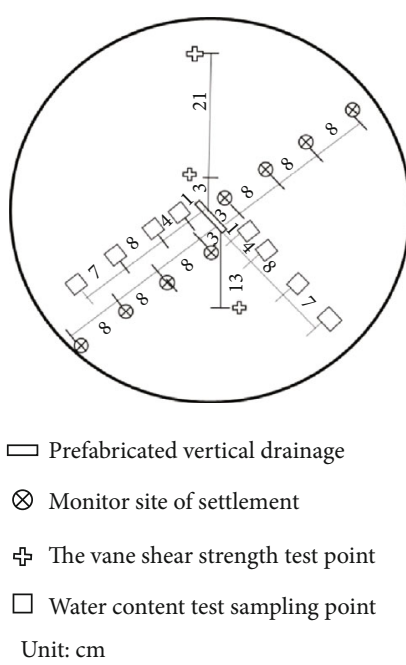

FIgURE 6: Schematic diagram of test points and sampling points.

drainage dewatering, clogging an increasing number of drainage channels. More drainage channels may be retained and achieve better results with the combination of other reagents with framework building effects such as $\mathrm{CaO}$ [15].

Figure 9 shows that the drainage conditions of case 1 and case 2 PVDs after conditioning were obviously different. The drainage rate of the case 1 model box of the test group using a separable PVD was lower than that of the case 1 and 2 model box using an integrated PVD during the whole experiment. This was because the core board of the separable PVD (case 1) was not bonded with the filter membrane. Under the action of large vacuum pressure, the filter membrane was easily pressed into the groove of the core board and clogged the drainage channel, reducing the water through the capacity of the PVD. Due to the continuous gap between

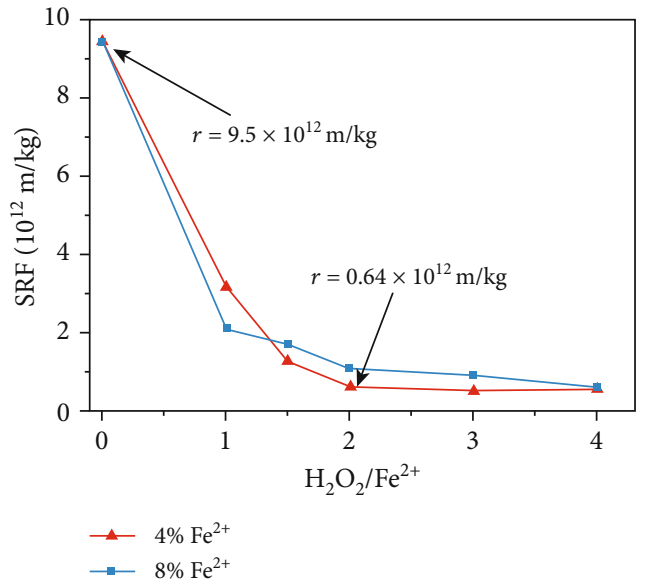

FIgURE 7: Relationship curve between the specific resistance and mixture ratio of the reagent.

the drainage rates of case 1 and case 2, after 312 hours of vacuum preloading, case 1 drained a total of $9350 \mathrm{~mL}$ while case 2 drained a total of $15700 \mathrm{~mL}$. The total discharge capacity of case 2 was 1.68 times that of case 1 . Since the original sludge was not treated with reagents, although it used the integrated PVD, the drainage effect was still poor, which was only $3100 \mathrm{~mL}$, much lower than that of case 1 drained by the separable PVD after conditioning. When the same reagents were used for the vacuum reinforcement, the drainage effect of the separable PVD was not as good as that of the integrated PVD.

3.2.2. Sludge Surface Settlement. During the test, eight points were selected on the diameter of a certain vertical PVD to monitor and record the sludge settlement. The settlement of each point was different, but it was symmetrically distributed around the PVD. Therefore, four monitoring points on the radius were selected to make their settlement curves, as shown in Figure 10.

It can be seen from the figure that the settlement curve of each point had a sudden increase after 24 hours. This was because of the vacuum pressure adjustment (adjusted from $40 \mathrm{kPa}$ to $80 \mathrm{kPa}$ ); by observing the steepness of the settlement curves, the slope gradually decreased over time. The settlement curves presented the characteristics of being fast first and then slow, which was consistent with the drainage characteristics. The trend of the settlement in the test is the same as Lin et al. and Wu et al. [4, 19].

In the process of settlement, the settlement value of each point on the same diameter was different. The farther away from the PVD, the greater the settlement value, while the closer to the PVD, the smaller the settlement value. This may be related to the formation of soil piles. The settlement conditions of case 1 and case 2 were basically the same. The maximum settlement value of case 2 was $7.3 \mathrm{~cm}$, and the maximum settlement value of case 1 was $6 \mathrm{~cm}$. Figure 10 shows that although the monitoring points were evenly distributed, the settlement values did not increase uniformly along the radius. Instead, the farther away from the PVD, the faster the settlement rate and the larger the settlement value. 


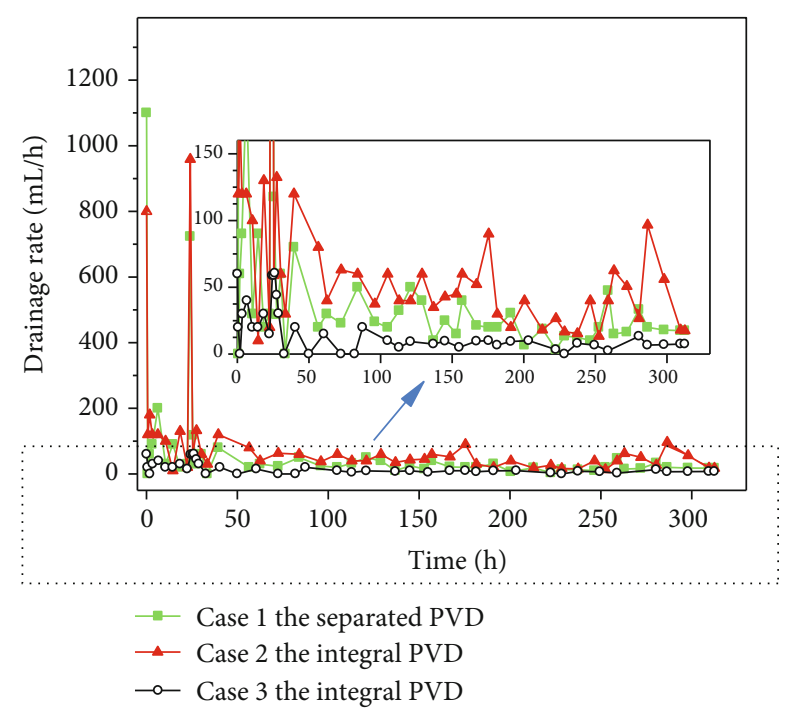

Figure 8: Variation curve of the drainage rate with time.

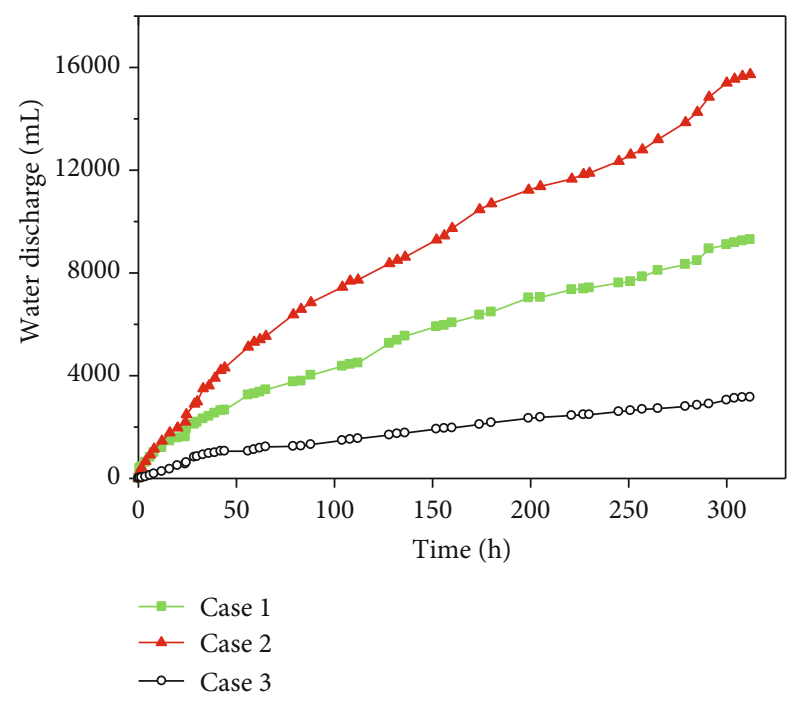

FIgURE 9: Curve of water discharge with time.

The average settlement value of the selected 8 points was used as the cumulative settlement value of the sludge to obtain the relationship between the cumulative settlement of the sludge and the time. The curves are shown in Figure 11.

Figure 11 shows that the changes in the cumulative settlement of the test group can be roughly divided into two stages, namely, stage 1 and stage 2 . The loading of $40 \mathrm{kPa}$ in the early 24 hours of vacuum preloading is stage 1, and vacuum preloading up to $80 \mathrm{kPa}$ is classified as stage 2 . The average settlement rate of all cases changes greatly when the load suddenly increases to $80 \mathrm{kPa}$, which is consistent with the curve of water discharge. Vacuum preloading is applied in stages to effectively increase the drainage effect in the vacuum preloading stage.

Figure 11 shows that the cumulative settlement of case 2 was the largest, which was $6.4 \mathrm{~cm}$, followed by case 1 , which was $5.4 \mathrm{~cm}$. Case 3 had the smallest settlement, which was less than $2 \mathrm{~cm}$; these three settlement curves had a sudden increase after 24 hours. The slopes of the settlement curves became smooth, indicating that the settlement rates decreased with time, which was related to the decrease in the drainage rate with time. The cumulative average settlement of case 1 with the separable PVD was slightly smaller than that of case 1 with the integrated PVD, which was significantly larger than the original sludge without reagent conditioning.

\subsubsection{Moisture Content}

(1) Distribution in the Horizontal Direction. To study the distribution of the moisture content along the radial direction after vacuum preloading of different types of PVDs, several samples were taken along the radial direction to measure the moisture content in the case 1,2, and 3 model boxes after the test. The result is shown in Figure 12.

Figure 12 shows that the closer to the PVD, the smaller the moisture content. The moisture content close to the PVD was the smallest. The moisture content of case 2 was $66.0 \%$, that of case 1 was $66.5 \%$, and that of case 3 was $71.2 \%$. The distribution range of the moisture content along the radial direction was relatively large. For case 2, the distribution range increased from $66.0 \%$ to $72.0 \%$; for case 1 , it increased from $66.5 \%$ to $74.2 \%$; and for case 3, it increased from $71.2 \%$ to $75.5 \%$, with a span of more than $4 \%$.

At the position $5 \mathrm{~cm}$ away from the board, the distribution curve of the moisture content had a large turning point. The slope was much smaller after $5 \mathrm{~cm}$ than before $5 \mathrm{~cm}$, indicating that there was a dense low-permeability layer formed within $1 \sim 5 \mathrm{~cm}$ from the board [7]. The density of the sludge within $1 \sim 5 \mathrm{~cm}$ was different from that within $5 \sim 12 \mathrm{~cm}$. The permeability varied greatly. The changes in the moisture content in the radial direction of case 1 and case 2 were similar, indicating that the PVD type had no effect on the distribution of the moisture content in the radial direction. However, the distribution curve of the moisture content of case 2 was always below that of case 1 . Different types of PVDs resulted in different moisture contents in the same position, which was directly related to different discharge capacities caused by the different types of PVDs.

The distribution of the moisture content in the radial direction showed a rule that the farther away from the PVD, the higher the moisture content, which was related to the decline rule of the vacuum degree. During vacuum preloading, the vacuum degree gradually declined along the radius and depth directions with PVD as the center [34]. Moreover, a vacuum seepage field in the shape of a depression cone with a convex bottom would be gradually formed over time. The reinforcement range was the area developed by the depression cone [35].

(2) Distribution in the Vertical Direction. To study the vertical distribution of the moisture content of the sludge after different types of PVDs were used for vacuum preloading, the moisture content was measured at positions away from the PVD with distances of $1 \mathrm{~cm}, 5 \mathrm{~cm}, 13 \mathrm{~cm}$, and $20 \mathrm{~cm}$ 


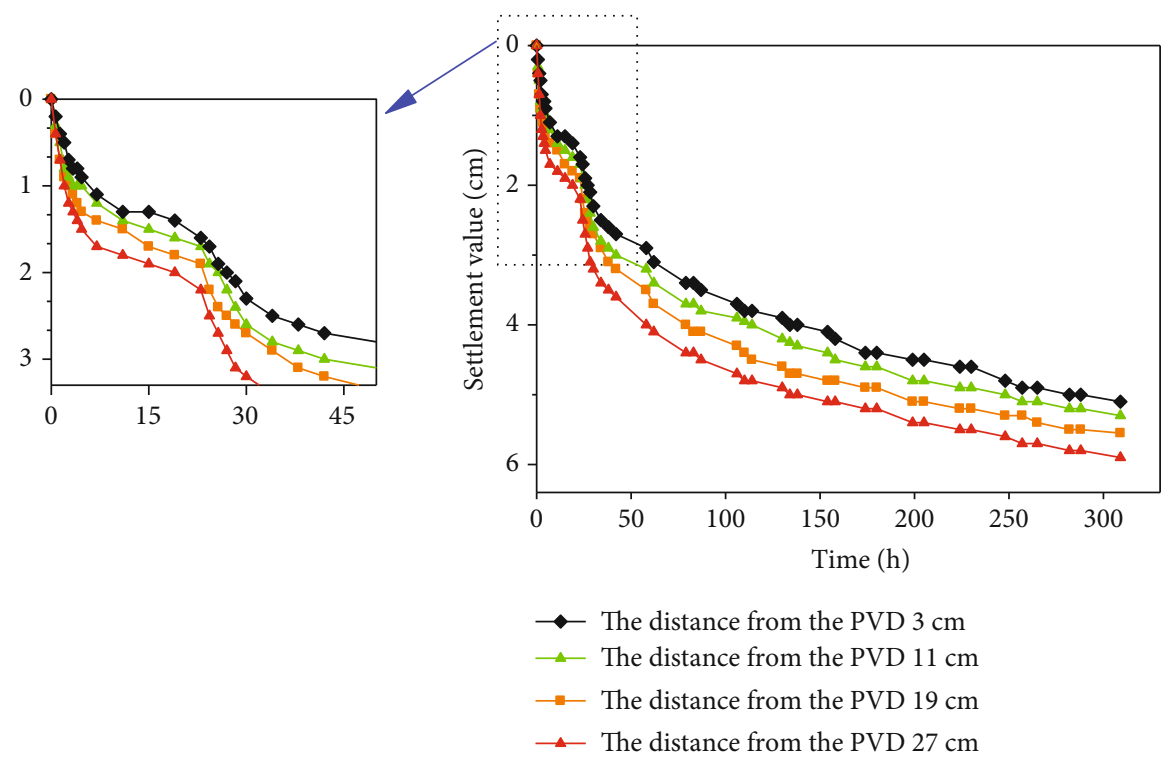

(a) Case 1

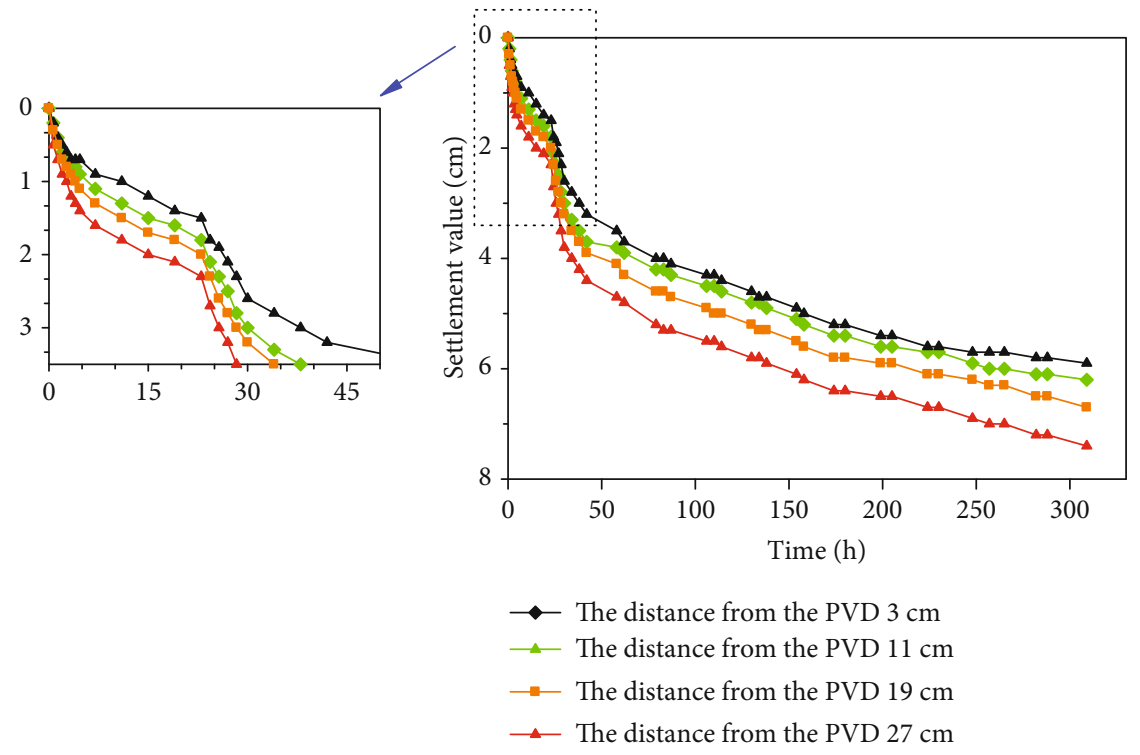

(b) Case 2

Figure 10: Settlement law of the monitoring point.

vertically at depths of $0 \mathrm{~cm}, 10 \mathrm{~cm}$, and $20 \mathrm{~cm}$, respectively. The vertical distribution of the moisture content is shown in Figure 13.

Figure 13 shows that the distribution of the moisture content of the three groups of model boxes changed considerably compared with the conditions before vacuum preloading. The moisture content was not homogeneously distributed. The moisture content was the smallest at depths of $0 \mathrm{~cm}$ and $1 \mathrm{~cm}$ from the board. The moisture content was the largest at $20 \mathrm{~cm}$. Through careful observation of Figure 13, it can be found that the moisture content of case 1 within the depth range of $10 \mathrm{~cm} \sim 20 \mathrm{~cm}$ had a great turning point compared to that within the depth range of $0 \sim 10 \mathrm{~cm}$, indicating that the moisture content was distributed more even than that within the depth range of 10 20 cm; the moisture content of case 2 had a smaller change in the surface layer than that at depths of $10 \mathrm{~cm}$ and $20 \mathrm{~cm}$, indicating that the moisture content in the upper part was distributed more evenly than that in the lower part after vacuum preloading. The PVD type had no obvious influences on the vertical distribution of the moisture content.

At the same time, it can also be seen that when the distance from the PVD was constant, there was a rule that the deeper the depth, the larger the moisture content along the depth direction, which may be related to the attenuation of the vacuum in the depth direction. The farther away from the PVD, the greater changes in the moisture content along the depth direction, indicating that the further away from the PVD, the faster the vacuum loss rate and the greater the vacuum loss. 


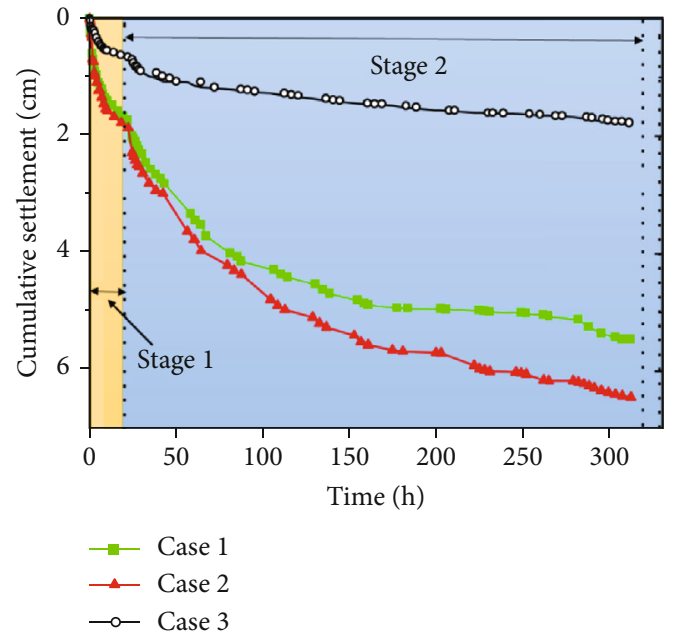

FIgURE 11: Cumulative settlement curve with time.

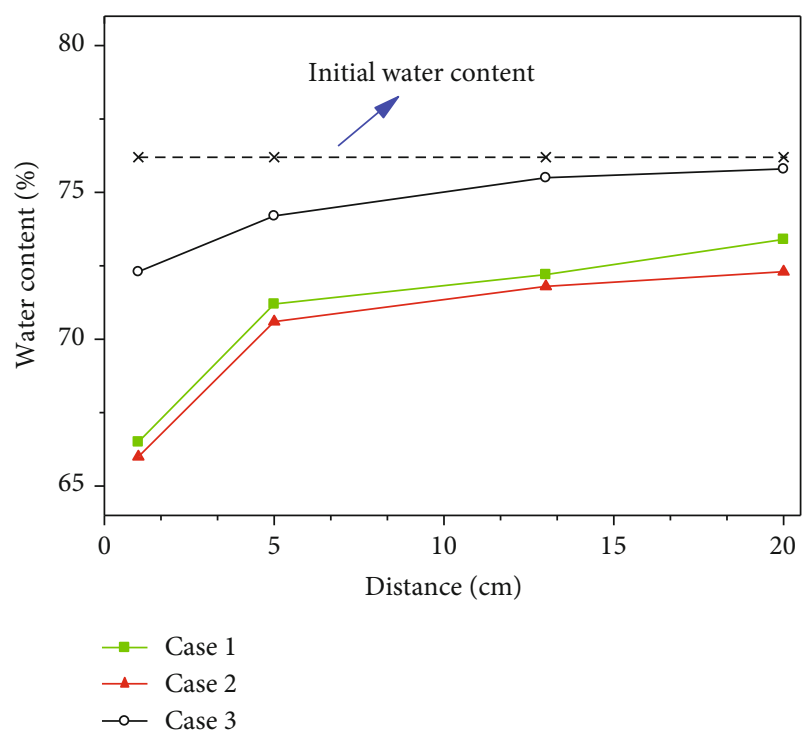

FIgURE 12: Radial moisture content distribution curve.

3.2.4. Shear Strength. To study the shear strength distribution of the sludge at different depths and distances from the PVD after different types of PVDs were used for vacuum preloading, after unloading, vane shear tests were carried out at positions $3 \mathrm{~cm}$ and $13 \mathrm{~cm}$ away from the PVD at depths of $15 \mathrm{~cm}$ and $30 \mathrm{~cm}$. The undrained shear strength of remolded soil should be measured after the peak strength or stable value strength appears and then rotated continuously along the direction of shear torsion for 6 turns. The results are shown in Table 5.

Table 5 shows the shear strength of case 3 after vacuum preloading was still rather low, and the shear strength of case 1 and case 2 had increased to different degrees, but the strength distribution was inhomogeneous; case 2 had the highest shear strength, with a maximum value of $5.8 \mathrm{kPa}$, followed by case 3 with a maximum value of $3.4 \mathrm{kPa}$ and case 3 with a minimum value of $1.1 \mathrm{kPa}$; the shear strengths of case 1 and case 2 at a distance of $3 \mathrm{~cm}$ from the PVD were 3.4 times and 4.1 times those at $13 \mathrm{~cm}$, respectively, indicating that dense "soil piles" with poor permeability were formed near the PVD $[29,36,37]$. The soil piles were formed by the movement and aggregation of fine particles towards the PVD under the action of permeability. The strength was larger than that of the surrounding soil [19]. The lower the moisture content is, the higher the shear strength near the PVD.

It can be seen from the table that the strength of case 2 remodelled sludge was much lower than that of in situ strength, followed by case 1 . Case 2 was the most sensitive and structurally strongest. The sensitivity of case 3 was basically not structural between 1.0 and 1.4. The sensitivities of the three groups of sludge were below 2.0, which were all low-sensitivity soils. There was still some gap in the remodelled strengths of the three groups of tests at the position $3 \mathrm{~cm}$ from the PVD. The remodelled strengths were basically the same at the position $13 \mathrm{~cm}$ from the PVD. This showed that a dense sludge layer was formed between $3 \mathrm{~cm}$ and $13 \mathrm{~cm}$, which affected the dewatering of the sludge far away from the PVD, making the sludge strength distribution extremely inhomogeneous.

The shear strength was the greatest at the position close to the PVD. The farther the distance from the PVD is along the radial direction, the lower the strength, and the deeper along the depth direction, the lower the strength. The shear strength after vacuum preloading presented the abovementioned law, which may be due to the gradual attenuation of the vacuum degree along the radial and depth directions [7]. The shear strengths of the three groups were far from reaching the landfill standard stipulated by the state. The vacuum preloading performance can be improved by adding curing reagents and reducing the PVD spacing.

3.2.5. PVD. The PVDs before and after vacuum preloading are shown in Figure 14.

The PVD was connected to the vacuum source through a flat joint and a thin tube, undertaking the dual functions of transmitting vacuum pressure and draining water. After 15 days of vacuum preloading, the filter membrane and the core board of the PVD were reddish-brown with obvious stratifications. The colour gradually became lighter from top to bottom. This indicated that the degree of chemical reactions inside the sludge was inhomogeneous after the reagent was added. The closer to the bottom of the model box, the less sludge that can fully react with Fenton's reagent. The upper reaction was the most violent and sufficient, while the middle and lower chemical reaction degrees decreased successively. The even mixture determined the uniformity of the sludge and the reagent. It is especially important to explore new mixing methods to make the upper and lower parts of the sludge fully react with the reagent.

During the vacuum preloading test, PVD clogging and bending were two important factors affecting the effect of soil reinforcement. Generally, PVD clogging can be divided into filter clogging and core board clogging. PVD bending can be divided into Z-shaped, S-shaped, and other forms [38]. It may be that the depth of the test treatment was not deep 


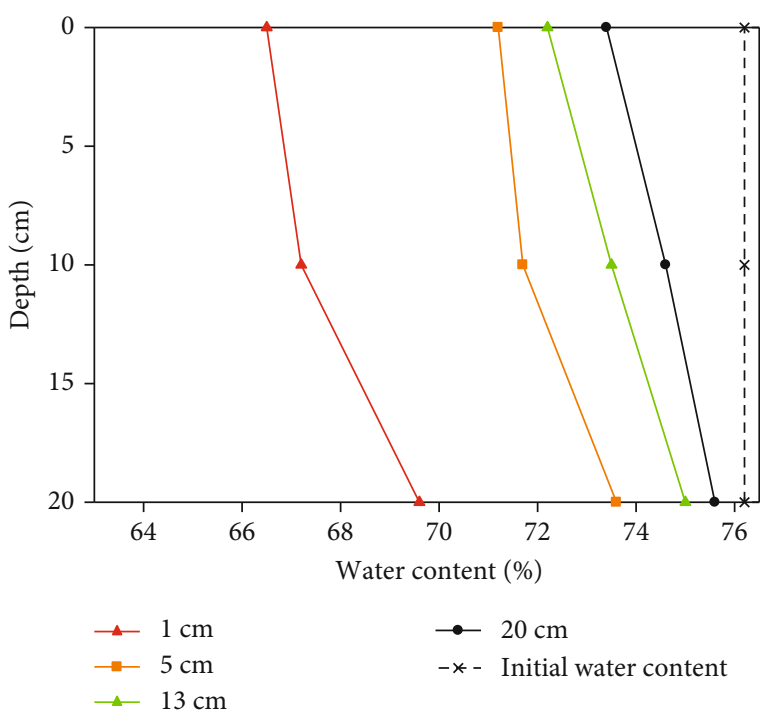

(a) Water content distribution of case 1

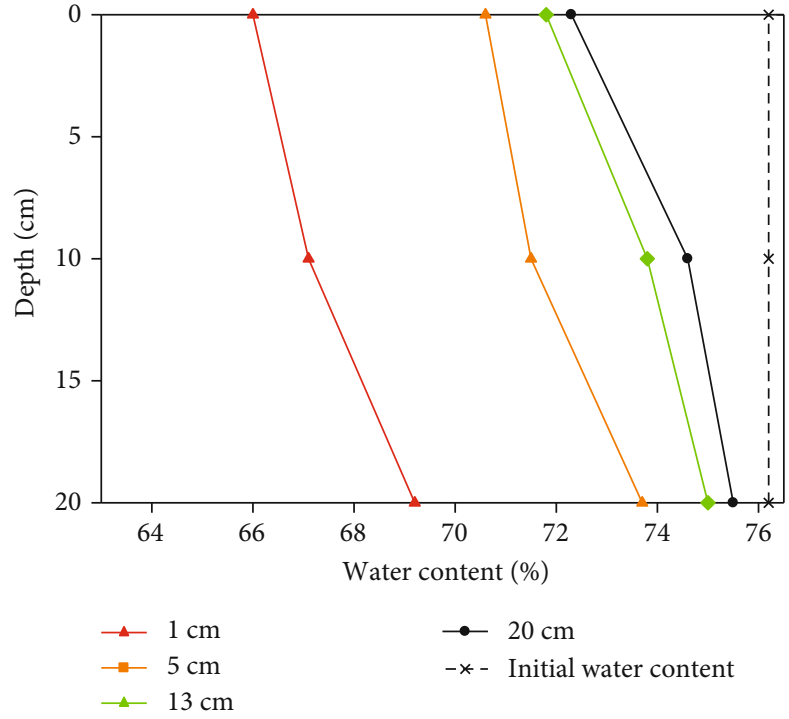

(b) Water content distribution of case 2

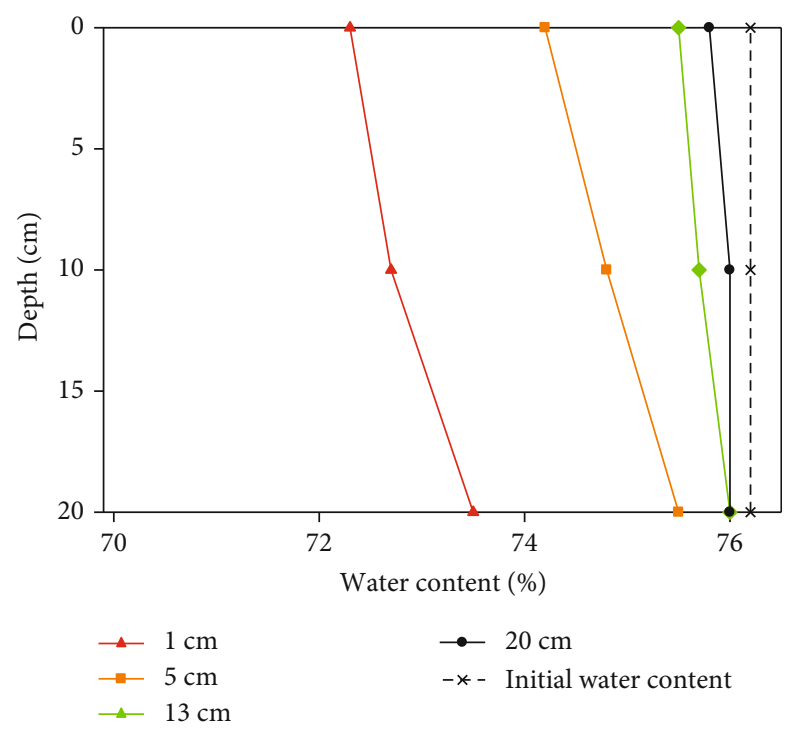

(c) Water content distribution of case 3

FIGURE 13: Vertical moisture content distribution curve.

TABLE 5: Shear strength of sludge.

\begin{tabular}{|c|c|c|c|c|c|c|c|c|c|c|}
\hline \multirow[t]{2}{*}{$\begin{array}{l}\text { Depth } \\
(\mathrm{cm})\end{array}$} & \multirow[t]{2}{*}{$\begin{array}{l}\text { The distance } \\
\text { from the board } \\
\qquad(\mathrm{cm})\end{array}$} & \multicolumn{3}{|c|}{$\begin{array}{l}\text { Strength of } \\
\text { sludge } \\
(\mathrm{kPa})\end{array}$} & \multicolumn{3}{|c|}{$\begin{array}{l}\text { Remodeled } \\
\text { strength of } \\
\text { sludge } \\
(\mathrm{kPa})\end{array}$} & \multicolumn{3}{|c|}{ Sensitivity } \\
\hline & & 1 & 2 & 3 & 1 & 2 & 3 & 1 & 2 & 3 \\
\hline \multirow{3}{*}{15} & 3 & 3.4 & 5.8 & 1.4 & 2.0 & 3.1 & 1.0 & 1.7 & 1.9 & 1.4 \\
\hline & 13 & 1.0 & 1.4 & 1.1 & 0.6 & 0.8 & 1.0 & 1.0 & 1.7 & 1.0 \\
\hline & 24 & 0.6 & 1.0 & 0.6 & 0.6 & 0.8 & 0.6 & 1.0 & 1.2 & 1.0 \\
\hline \multirow{3}{*}{30} & 3 & - & 4.0 & - & - & 1.9 & - & - & 2.1 & - \\
\hline & 13 & - & 1.0 & - & - & 0.7 & - & - & 1.4 & - \\
\hline & 24 & - & 0.6 & - & - & 0.6 & - & - & 1.0 & - \\
\hline
\end{tabular}

Note: the vane shear strength test is an in situ test of soil shear strength, which does not need to prepare remodeled sludge samples. and the PVD was short, so there was no bending phenomenon in either type of PVD. After vacuum preloading on the PVDs of cases 1 and 2, the colour changed from white to reddishbrown. There were some reddish-brown particles attached to the filter membrane, indicating the occurrence of clogging. The sludge itself had small particles. Coupled with the oxidation cracking effect of the Fenton process [32], the contents of clay and colloidal particles were further increased. Under the action of vacuum pressure, small particles (mainly clay and colloidal particles) transferred and aggregated to the drain, clogging the PVDs of case 1 and case 2.

In addition, case 1 separable PVD also accumulated a large number of dark-brown small particles on the upper part of the core board. These small particles accumulated in the upper groove of the core board by the filter membrane, clogging part of the drainage channels and enhancing the 


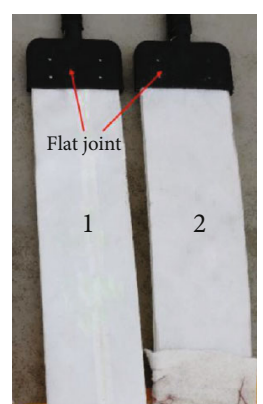

(a) Before vacuum preloading

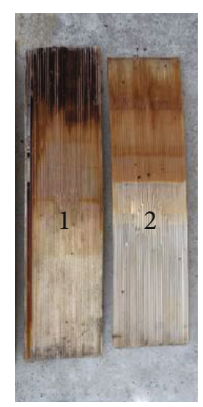

(b) After vacuum preloading
Figure 14: PVD before and after the test.

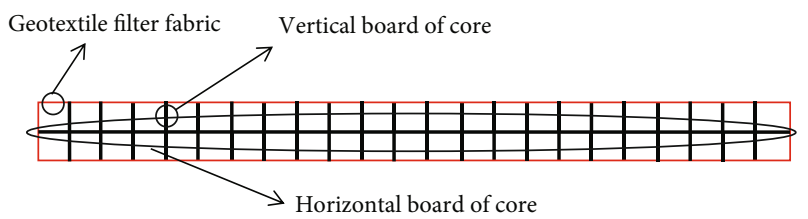

FIgURe 15: Cross section of PVD.

resistance effect. The separated drain board has a larger filter membrane area. During vacuum filtration, in the process of sludge soil particles accumulating towards the PVD under the action of vacuum loading, the filter membrane is extruded into the groove of the plastic board. The core board clogging of case 1 separable PVD reduced its own water through capacity, which was the direct reason for the drainage rate and discharge capacity of case 1 not as good as those of case 2. The root cause was the separation of the membrane core board from the separable PVD. When the vacuum preloading method was used to treat sludge, silt, and other particle-graded mud, integrated PVD was used.

Another possible reason is that the earth pressure on the geotextile filter fabric of integral PVD can be uniformly transmitted to the vertical board of the core (as shown in Figure 15). However, for the separated PVD, because the geotextile filter fabric is separated from the vertical board of the core, the force of the middle vertical board of the core is much higher than that of the plate near both sides. Due to the high force, the middle vertical board of the core is unstable and the middle channel of the PVD collapses.

\section{Conclusions}

This paper used different types of PVDs to conduct vacuum preloading and model tests on long-term landfill sludge modified by the Fenton process. The following conclusions are obtained:

(1) After conditioning by the Fenton process, the sludge drainage rate was accelerated, the discharge capacity was significantly improved, and the dewatering time was greatly shortened. The drainage rate of case 2 with the integrated PVD was always slightly higher than that of case 1 with the separable PVD. The discharge capacity of case 2 was 1.68 times that of case 1
(2) The average moisture contents of case 1 and case 2 after vacuum preloading dropped from $76.2 \%$ to $74.3 \%$ and $72.7 \%$, respectively, with a difference of $1.5 \%$. The cumulative settlement of case 2 was $6.4 \mathrm{~cm}$, which was 1.2 times that of case 3 . The deep dehydration reduction effect of the integrated PVD was slightly better than that of the separable PVD

(3) The moisture content distribution law of case 1 and case 2 was as follows: under the same depth, the farther away from the PVD, the greater the moisture content; when the distance from the PVD was the same, the deeper the depth, the greater the moisture content; the soil strength was the greatest near the PVD, which gradually decreased along with the radial and depth directions. The PVD had no obvious influence on the moisture content and intensity distribution

(4) After vacuum preloading, the PVDs of case 1 and case 2 both showed layered staining. A large number of dark-brown small particles on the upper part of the core board of the separable PVD in case 1 were clogged, indicating that the separable PVD was more likely to be clogged than the integrated PVD due to its structural characteristics

\section{Data Availability}

The data (figures and tables) used to support the findings of this study are included within the article.

\section{Conflicts of Interest}

The authors declare that they have no competing interests.

\section{Authors' Contributions}

Yitian $\mathrm{Lu}$ contributed to conceptualization, data curation, and formal analysis and wrote the original draft. Yajun $\mathrm{Wu}$ contributed to conceptualization, project administration, resources, and supervision and reviewed and edited the manuscript. Qingyang Deng contributed to data curation and reviewed and edited the manuscript. Binjie Song contributed to conceptualization and reviewed and edited the manuscript. Guang Chen contributed to project administration and resources and reviewed and edited the manuscript.

\section{Acknowledgments}

The authors are grateful for the financial support for the study presented in this paper from the National Natural Science Foundation of China (Grant No. 41772303).

\section{References}

[1] D. Elalami, H. Carrere, F. Monlau, K. Abdelouahdi, A. Oukarroum, and A. Barakat, "Pretreatment and codigestion of wastewater sludge for biogas production: recent research advances and trends," Renewable and Sustainable Energy Reviews, vol. 114, article 109287, 2019. 
[2] N. Buyukkamaci, "Biological sludge conditioning by Fenton's reagent," Process Biochemistry, vol. 39, no. 11, pp. 15031506, 2004.

[3] W. Wang, Y. Luo, and W. Qiao, "Possible solutions for sludge dewatering in China," Frontiers of Environmental Science and Engineering, vol. 4, no. 1, pp. 102-107, 2010.

[4] W. Lin, X. Zhan, L. Zhan, Y. Chen, Y. Jin, and J. Jiang, "Effect of $\mathrm{FeCl}_{3}$-conditioning on consolidation property of sewage sludge and vacuum preloading test with integrated PVDs at the Changan landfill, China," Geotextiles and Geomembranes, vol. 42, no. 3, pp. 181-190, 2014.

[5] L. Zhan, X. Zhan, W. Lin, X. Luo, and Y. Chen, "Field and laboratory investigation on geotechnical properties of sewage sludge disposed in a pit at Changan landfill, Chengdu, China," Engineering Geology, vol. 170, pp. 24-32, 2014.

[6] Y. Lu, S. Liu, Y. Zhang, M. Yang, Z. Fu, and L. Wang, "Sustainable reuse of coarse aggregates in clay-based impervious core: compactability and permeability," Journal of Cleaner Production, vol. 308, article 127011, 2021.

[7] L. Zhan, P. Zhang, X. Zhang, and W. Lin, "Experimental study on the control effect of chemical conditioning on low permeable layer in vacuum preloading process of municipal sludge," Journal of Southeast University (Natural Science), vol. 46, no. S1, pp. 7-13, 2016.

[8] T. Pham-anh and M. Slillanpaa, "Effect of freeze/thaw conditions, polyelectrolyte addition, and sludge loading on sludge electro-dewatering process," Chemical Engineering Journal, vol. 164, no. 1, pp. 85-91, 2010.

[9] W. D. Chanaka Udayanga, A. Veksha, A. Giannis et al., "Insights into the speciation of heavy metals during pyrolysis of industrial sludge," Science of the Total Environment, vol. 691, pp. 232-242, 2019.

[10] H. Xu, K. Shen, T. Ding, J. Cui, M. Ding, and C. Lu, "Dewatering of drinking water treatment sludge using the Fenton-like process induced by electro-osmosis," Chemical Engineering Journal, vol. 293, pp. 207-215, 2016.

[11] Y. Cao and C. Yin, "Engineering properties and landfill of stabilized sludge," Applied Mechanics and Materials, vol. 295-298, pp. 1751-1754, 2013.

[12] A. Kelessidis and A. Stasinakis, "Comparative study of the methods used for treatment and final disposal of sewage sludge in European countries," Waste Management, vol. 32, no. 6, pp. 1186-1195, 2012.

[13] C. Chen, P. Zhang, G. Zeng, J. Deng, Y. Zhou, and H. Lu, "Sewage sludge conditioning with coal fly ash modified by sulfuric acid," Chemical Engineering Journal, vol. 158, no. 3, pp. 616$622,2010$.

[14] Y. Dai, S. Huang, J. Liang et al., "Role of organic compounds from different eps fractions and their effect on sludge dewaterability by combining anaerobically mesophilic digestion pretreatment and Fenton's reagent/lime," Chemical Engineering Journal, vol. 321, pp. 123-138, 2017.

[15] W. Ren, Z. Zhou, L. Jiang et al., "A cost-effective method for the treatment of reject water from sludge dewatering process using supernatant from sludge lime stabilization," Separation and Purification Technology, vol. 142, pp. 123-128, 2015.

[16] W. Wu, Z. Zhou, J. Yang et al., "Insights into conditioning of landfill sludge by $\mathrm{FeCl}_{3}$ and lime," Water Research, vol. 160, pp. 167-177, 2019.

[17] B. Albert, "Filter press, particularly for dewatering sludge in sewage treatment plants," US Patent 3896030. 1975-7-22.
[18] H. Lori and H. Robert, "Water/sludge filter press," US Patent 6135293.2000-10-24.

[19] Y. Wu, Y. Xu, X. Zhang et al., "Experimental study on vacuum preloading consolidation of landfill sludge conditioned by Fenton's reagent under varying filter pore size," Geotextiles and Geomembranes, vol. 49, no. 1, pp. 109-121, 2021.

[20] Y. Wu, Y. Xu, X. Zhang et al., "Experimental study on treating landfill sludge by preconditioning combined with vacuum preloading: effects of freeze-thaw and $\mathrm{FeCl}_{3}$ preconditioning," Science of the Total Environment, vol. 747, article 141092, 2020.

[21] X. Zhang, Y. Lu, J. Yao, Y. Wu, Q. C. Tran, and Q. V. Vu, "Insight into conditioning landfill sludge with ferric chloride and a Fenton reagent: effects on the consolidation properties and advanced dewatering," Chemosphere, vol. 252, pp. 126528-126528, 2020.

[22] Y. Lu, J. Chai, and W. Ding, "Predicting deformation of PVD improved deposit under vacuum and surcharge loads," Geotextiles and Geomembranes, vol. 48, pp. 32-40, 2019.

[23] E. Neyens, J. Baeyens, M. Weemaes, and B. de heyder, "Pilotscale peroxidation $\left(\mathrm{H}_{2} \mathrm{O}_{2}\right)$ of sewage sludge," Journal of Hazardous Materials, vol. 98, no. 1-3, pp. 91-106, 2003.

[24] M. Tony, Y. Zhao, J. Fu, and A. M. Tayeb, "Conditioning of aluminium-based water treatment sludge with Fenton's reagent: effectiveness and optimising study to improve dewaterability," Chemosphere, vol. 72, no. 4, pp. 673-677, 2008.

[25] Y. Wu, X. Wang, X. Zhang et al., "Experimental study on the treatment of sludge discharged from an in situ soil washing plant by vacuum preloading," Environmental Engineering Science, 2021.

[26] P. Wang, Y. Han, J. Wang, Y. Cai, and X. Geng, "Deformation characteristics of soil between prefabricated vertical drains under vacuum preloading," Geotextiles and Geomembranes, vol. 47, no. 6, pp. 798-802, 2019.

[27] I. Lo, C. Lai, and G. Chen, "Salinity effect on mechanical dewatering of sludge with and without chemical conditioning," Environmental Science and Technology, vol. 35, no. 23, pp. 4691-4696, 2001.

[28] P. Carman, "Fundamental principles of industrial filtration (a critical review of present knowledge)," Transactions of Institution of Chemical Engineers, vol. 16, pp. 168-188, 1938.

[29] J. Wang, Y. Yang, H. Fu et al., "Improving consolidation of dredged slurry by vacuum preloading using prefabricated vertical drains (PVDs) with varying filter pore sizes," Canadian Geotechnical Journal, vol. 57, no. 2, pp. 294-303, 2020.

[30] W. Xie, J. Wang, H. Fu et al., "Effect of pressurization positions on the consolidation of dredged slurry in air-booster vacuum preloading method," Marine Georesources and Geotechnology, vol. 38, no. 1, pp. 122-131, 2020.

[31] China Building Industry Press, Ministry of Housing and Urban-Rural Development, PRC National Development and Reform Commission, PRC Technical Guide for Sludge Treatment and Disposal in Urban Sewage Treatment Plants, 2012.

[32] W. Yu, J. Yang, Y. Shi et al., "Roles of iron species and pH optimization on sewage sludge conditioning with Fenton's reagent and lime," Water Research, vol. 95, no. 3, pp. 124-133, 2016.

[33] C. Chen, X. Bo, Y. Ren, C. Wu, and C. Wei, "The action mechanism of Fenton reagent for treating various influencing factors in wastewater," Environmental Science, vol. 21, no. 3, pp. 93-96, 2000.

[34] Q. Zhu, C. Gao, S. Yang, L. Zhang, D. Li, and Z. Wang, "Study on vacuum transfer characteristics in ultra-soft silt foundation 
treatment," Journal of Geotechnical Engineering, vol. 32, no. 9, pp. 1429-1433, 2010.

[35] Q. Li, A. Wu, Z. Yao, and J. Huang, "Discussion on the formation mechanism of vacuum seepage field," Mining Research and Development, vol. 24, no. 6, pp. 17-20, 2004.

[36] Y. Deng, L. Liu, Y. Cui, Q. Feng, X. Chen, and N. He, "Colloid effect on clogging mechanism of hydraulic reclamation mud improved by vacuum preloading," Canadian Geotechnical Journal, vol. 56, no. 5, pp. 611-620, 2019.

[37] J. Wang, J. Ma, F. Liu et al., "Experimental study on the improvement of marine clay slurry by electroosmosisvacuum preloading," Geotextiles and Geomembranes, vol. 44, no. 4, pp. 615-622, 2016.

[38] Y. Cai, H. Qiao, J. Wang, X. Geng, P. Wang, and Y. Cai, "Experimental tests on effect of deformed prefabricated vertical drains in dredged soil on consolidation via vacuum preloading," Engineering Geology, vol. 222, pp. 10-19, 2017. 